\title{
Investigating the Impact of Internet Dependency on Student-Teachers' Loneliness of Adiyaman University
}

\author{
Kürşat Yusuf Aytaç \\ Correspondence: Kürşat Yusuf Aytaç, Adiyaman University, School of Physical Education and Sport, Turkey. \\ Received: December 10, 2017 \\ Accepted: January 21, $2018 \quad$ Online Published: January 23, 2018 \\ doi:10.11114/jets.v6i2.2848 \\ URL: https://doi.org/10.11114/jets.v6i2.2848
}

\begin{abstract}
This research was conducted to investigate the effect of internet dependency on student- teachers' loneliness of Admiyaman University. The study also examined the differences in internet dependency and loneliness among students and teachers of Adiyaman University of Turkey. The standard questionnaire of Jung (1996) was used to measure the internet dependency. Also, to measure the sense of loneliness variable, the standard questionnaire of Rosell et al. (1980) was used. The reliability of the questionnaires was evaluated using Cronbach's alpha test, which included: Internet addiction questionnaire 0.91 and loneliness questionnaire 0.86. Questionnaires were distributed among the subjects (172 student- teachers of Adiyaman University). The results showed that internet dependency on student- teachers' loneliness of Adiyaman University had a significant positive effect (beta $=0.898$ ). There was also a significant difference between the dependence on the internet and the feelings of the student- teachers of Adiyaman University of Turkey. Male student- teachers were more dependent on the internet, and female student- teachers also felt more lonely.
\end{abstract}

Keywords: internet, dependency, loneliness, Adiyaman University, Turkey

\section{Introduction}

Internet access is a growing phenomenon, and more and more people are the internet users every day. The Internet is used everywhere, like home, school and university. In fact, today learning to use the internet seems to be necessary for all people. Statistics show that in recent years, the number of internet users has risen steadily (Tony O'Neill et al., 2014: 1053).

With the ever-increasing availability of people to the internet, a new kind of addiction has been induced to the internet and which is a growing awareness of the age of information. Like other types of addiction, internet addiction is associated with symptoms such as depression, tearfulness, agitation, disruption of social relationships, and academic failure. According to Douglas and colleagues, internet addiction is defined as the extreme compulsive use of the tool, which, in the event of being deprived of it, is highly irritable, displays self-behaved behaviors (quoted; Bepta et al. 2015: 17). This type of dependency is an inability to control the use of the internet, which slowly leads to uncomfortable feelings and a weakening of the daily activities. From a practical point of view, internet dependency has the ability to influence career life, lifestyle and even place of residence due to social, psychological and emotional outcomes (Kos and Griffiths, 2015: 102).

Riding and colleagues also believe that one of the main reasons for these tendencies is social, friendship and recreational support, which, due to the wide range of communication, career, family and marital problems (Walfing, 2015: 103). Van der Aa et al. found that daily use of the Internet is indirectly related to the low level of individual well-being and the compulsory use of it with personality traits of introversion, incompatibility and low emotional stability (quoted by Müller et al., 2014: 772). The increasing amount of research on internet addiction suggests that internet addiction disorder is a psychological-social disorder characterized by its characteristics, tolerance, withdrawal symptoms, emotional disturbances and social disruption (Huang and Colleagues, 2014: 12). Contrary to the fact that the "loneliness" of a positive concept meant that a person was voluntarily withdrawing from everyday life in order to achieve higher goals, in psychological texts, today, "loneliness" includes the main and important elements, such as the feeling of undesirable loss or lack of Losing companions are the unpleasant and negative aspects of lost relationships and loss of relationship with others. Therefore, loneliness is an experience due to the basic human need for belonging, which may be continuous or temporary (Chu et al., 2014: 512). Loneliness is a fundamental fact of life, and all people experience it in varying degrees in some periods of their lives. This situation occurs when there is a gap between the desired interpersonal relationships and the relationships that one has in the present. Loneliness is an uncomfortable emotional experience, but it also emphasizes the cognitive element. This is because loneliness stems from the perception that the individual's social communication does not meet some of his 
expectations (Goosents et al., 2015: 219).

Hamberger \& Ben-Artzi also studied the personality and emotional characteristics of Internet users in applying personality theory to the relationship between loneliness and internet. The results of their review showed that specific features such as introversion and loneliness lead to more use of the Internet (Cassiopeau et al., 2010: 460). According to the above, this study tries to investigate the impact of Internet dependency on student- teachers loneliness of Adiyaman University.

\section{Materials and Methods}

The purpose of this study is to investigate the effect of internet dependency on student-teachers' loneliness of Adiyaman University. In terms of data collection it is an applied one.

The statistical population of this study is all student- teachers of Adiyaman University, in number of 310, and a sample size of 172 was determined using Morgan table was selected by simple random sampling. To measure the internet dependency variable, the standard questionnaire of DSM-IV (Jung) (1996) has been used. Also, to measure the sense of loneliness variable, the standard questionnaire of Russell et al. (1980) has been used. In this study, based on the questionnaire's standardization, the validity of the questionnaire was carried out by the views of the professors and experts in order to be more reliable and according to the nature and objectives, and after validation of the questionnaire, it was able to perform. Cronbach's alpha test was used to measure reliability. The alpha coefficient for the internet addiction questionnaire is 0.91 and for the loneliness questionnaire is 0.86 . For the first test, one-way regression test and independent T-test were used for the rest tests.

\subsection{Internet Dependence}

Cognitive-behavioral view: Based on this view, a strong internet connection with the previous psychological conditions is created. When a person is exposed to the use of the internet, the problem of internet usage begins. This pathology is grounding in some kind of willingness and desire and causes stress (Zhou et al., 2012: 1112). Based on the theoretical model of Davies, a cognitive-behavioral theorist, loneliness caused by social isolation creates one's readiness to become addicted or addicted to the internet. One's belief that anyone outside the internet does not like him and the idea that does not socially supported by anyone, affects a person to addict the internet. According to Dr Davis, the possibility of a strong addicted to internet are among those individuals who have been isolated and confused and those who are in difficult social and interpersonal communication more than others (Quoted; according to Santos et al., 2015: 342).

\section{Theory of Mental and Personality Dynamics:}

This theory relates to the roots of a strong internet dependency with emotional shocks or childhood emotional deficits, personality traits, or other inherent disorders or mental states. According to this view, depending on the childhood events or personality traits acquired at adulthood, the individual is prone to developing an addictive behavior or any other behavior. In this case, what matters is not the subject or activity, but the individual and the basis upon which he becomes addicted (King et al., 2012: 1189).

Behavioral Explanation: This explanation is based on B. F. Skinner is a conditional agent or agent. According to this view, the person enters the internet to receive rewards. The rewards he takes of this behavior are to escape from reality, reach for a lot of love and hobbies, and if a person also needs these rewards in the future, he will probably come to the internet. And as a result, this process is strengthened and the cycle continues (Volvers et al., 2014: 1841).

Cognitive Explanation: This view emphasizes the way people take and interpret information and use them to solve problems rather than focusing on desires, needs and motivations. In this perspective, the internet is heavily dependent on faulty cognitive defects or cognitive defects, and its treatment is based on correcting the process of defective cognition (Winkler et al., 2013: 320).

\subsection{Signs of Internet Disease at Different Periods}

Signs of danger in preschool: There are mood swings in one or more days and more than fifteen minutes and parents, family members can no longer calm him. Aggressive behavior, and often without reason, is extremely active and fearless, consistently obeying commands and listening to older people ... (Mountain, 2015: 226).

Risk warning in primary school: He has difficult to focus and concentrate; his work at school is weak; he is constantly involved with other children at school; he shows reaction about the criticism of harassment or rage of blame or great revenge, he has little friends and is often rejected because of his behavior (Lopez Fernandez, 2015: 266).

Signs of danger in adolescence: He does not pay attention to the feelings or rights of others, ill-treats people, and it seems to rely on physical violence to solve its problems, absent from the class without reason, and engage in fights of theft or vandalism. He may use alcohol or tobacco ... (Pouli and Agrimi, 2012: 56). 
Signs of danger in students: failure in the course, loss of interest in attending classes, lack of motivation for study, less time to study, assigning and continuing to use the internet despite these negative consequences (Kim et al., 2013: 395).

Loneliness: Loneliness is considered as one of the symptoms of depression and as an independent factor in causing psychological harm.

Loneliness is a sign of deficiencies and deficiencies in the establishment of emotional and social connections. In other words, loneliness is a subjective and annoying experience that reveals shortcomings in interpersonal emotional and social connections. Someone may be in a group but not enjoyable social or emotional connections and complain of loneliness.

Historically, loneliness has been one of the complex psychological structures discussed among philosophers. At that time, the feeling of loneliness was a positive concept, meaning the voluntary withdrawal of the individual from the daily struggles of life to achieve higher goals such as thinking, meditation and communication with God. But in today's psychological texts, positive feelings of loneliness are not addressed. It also includes a situation in which a person perceives or experiences a lack of relationships with others and includes key elements such as the feeling of undesirable loss or loss of companion, the unpleasant and negative aspects of lost relationships, and loss. The quality level of relationships is different (Kalleter et al., 2015: 258).

The history of loneliness studies suggests that in the past, these structures were conceived with other problems, such as depression, shyness, anger, self-destructive behavior, and the like. But in new definitions and conceptualizations, the feeling of loneliness is considered a psychological structure independent of other problems that have its own unique dangers.

A review of the history of research in the definition of the sense of loneliness also shows that there are relatively significant differences between the experts in this regard. For example, some researchers consider loneliness as a psychological state due to quantitative and qualitative inadequacies in social relationships (Victor and Young, 2012: 93).

Based on theories such as Whiss, feeling loneliness is a severe negative experience that one avoids actively recalling. If he has to be reminded, he will do so with great discontent, and the lack of sense of loneliness will be less important. Wood makes such an insult that loneliness is a fundamental thrill and one of the strongest human experiences. He believes that a sense of association with a sense of loneliness points to the lack of appropriate social relations (Quoted by: Vandrool et al., 2011: 229).

According to Pepel and Perlman, cognition is the agent of mediation in loneliness. This representation of the cognitive approach is that loneliness is the consequence of the difference observed between several and the links that everyone hopes for. In the view of Pepel and Perlman, people may experience two loneliness. This view is based on the Weiss classification. In this classification, two types of loneliness - emotional solitude and social isolation - have been identified.

1. Emotional Loneliness: It does not result in an important attachment or loss of such a link.

2. Social loneliness: There is a lack of association with a social networking network, and may only be eliminated by achieving a desirable and pleasurable communication network (quoted by Victor et al. 2000: 412).

The etiology of loneliness: The emergence of loneliness is a complex process, and a number of factors, together, or apart from each other, reveal it and affect its dimensions. Everyone's perception of how social interactions is and how they interact as an internal factor in the formation of loneliness. A group of researchers believes that loneliness occurs when an exogenous factor, such as a deficiency in one's social networking network, arises and its needs for communication are less satisfying (Cacioppo, 2015: 241).

In this way, these factors can be considered in both internal and external categories.

Internal factors: A group of factors causing inner loneliness are one of those internal factors, cognitive errors, and irrational beliefs about emotional or social connections that lead to loneliness. Thinking that "there are negative personality traits in me that hate others" or "I can never find a friend because I do not feel any pain" or "I always spoil the connection with others", etc., is illogical thoughts. Low self-esteem or negative self-concept is also an internal factor. Perhaps the shortfall in one relationship reduces self-esteem. But self-esteem will also leave humans out of the effort to make friends with others (Shankar et al., 2013: 166).

External factors: One of the most important external factors is the lack of social skills. According to some experts, poor social skills may disrupt relationships. Maybe we are the only ones who do not know or think that we do not know how to treat others who are around us. Several studies on this issue show that lack of social skills makes people lonely. Such people spend their long and trouble staying connected with others and, with all their efforts, cannot initiate a sweet and heartfelt interaction with others and establish a close friendship with others (Hawkley and Caspio, 2010: 221).

Meanwhile, Cangier and Farrell reported that people who have social skills are more likely to speak, make eye contact, 
smile more and use more appropriate expressions than people who do not have social skills. In terms of epidemiology, according to Sapington's report, estimates of those who feel lonely in a lifetime range from $10 \%$ to $67 \%$. Demographic predictions in the United States in 1991 also showed that 29 million to 70 million Americans would feel lonely each month in 2000. The report shows that with each passing year, there has been an increasing trend in complaints of this feeling in individuals (quoted by Messi et al., 2011: 239).

Loneliness in neurotic diseases: Loneliness can be a precursor to a neurological disease. Psychological factors are involved in the development of psychological illnesses. These factors, although not acting on their own, but between them, require special attention to how interpersonal relationships in the phenomenon of mental illness are:

1. Inability to adapt to the demands of the periphery

2. Failure to deal with excitements and emotions and to show them how they are.

3. The inability to form rewarding or sustainable interpersonal links, in particular affiliated links (Shankar et al., 2013: 169).

Incongruity in mental illnesses shows the importance of ineffective interpersonal or emotional links in the emergence or appearance of mental illness. The psychosocial approach explains depression with the notion of losing or fearing the breakdown of links. Sigmund Freud, the tendency of depressed patients to bring back any kind of anger and hatred into oneself due to the loss of someone or something. Depression occurs when a patient finds out that the person or ideal he was living in was never such that he could estimate his expectations (Victor and Young, 2012: 95).

Many perspectives address the shortcomings of interpersonal ties. However, someone who is a mental model or an ideal model for linkage, loses its place in the cognitive and emotional construction of man. Either because he did not put out what human beings meant, or that the links (in the foundation) were made on the basis of loose and falsehood. Breaking down these special ties or creating defects in it causes depression. The semiotics of depression also involves loneliness, as the losing of pleasure to talk with others tends to disturb people in depressions (Cacioppo \& Hawkley, 2010: 226).

\section{Results}

Table 1. Summary of regression model for hypothesis 1 research

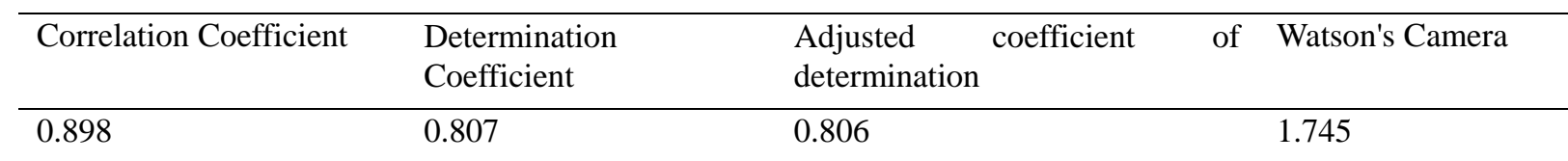

According to the results of table, the correlation coefficient between the dependence on the internet and the loneliness of the student-teachers of Adiyaman is 0.898 and the coefficient of determination is 0.807. If the camera-Watson statistic is within the acceptable range of 1.5 to 2.5 , a lack of correlation between the errors is accepted. Given that the Watson camera is 1.745 , it can be said that there is a lack of correlation between errors.

Table 2. One-way ANOVA results for hypothesis 1 of the research

\begin{tabular}{llllll}
\hline & TS & df & MS & F & Sig. \\
\hline Regression & 86.501 & 1 & 86.501 & 1085.87 & 0.000 \\
Difference & & 170 & 0.08 & & \\
Total & & 171 & & &
\end{tabular}

According to the results of the above table and considering that the significance level of the test error $\mathrm{f}$ is less than 0.01 for the confidence level of 0.99 , it can therefore be said that using the linear regression model to investigate the effect of Internet dependence on the loneliness of student- teachers of Adiyaman University of Turkey is possible and or, in other words, the independent variable can predict the dependent variable.

Table 3. Results of single-variable regression coefficient

\begin{tabular}{|c|c|c|c|c|c|}
\hline \multirow[t]{2}{*}{ Predicted variable } & \multicolumn{2}{|c|}{$\begin{array}{l}\text { non-standard } \\
\text { coefficients }\end{array}$} & \multirow{2}{*}{$\begin{array}{l}\begin{array}{l}\text { standard } \\
\text { coefficients }\end{array} \\
\text { BETA }\end{array}$} & \multirow[t]{2}{*}{$\mathrm{T}$} & \multirow[t]{2}{*}{$\mathrm{P}$} \\
\hline & B & $\mathrm{SE}$ & & & \\
\hline Fixed value & 0.288 & 0.102 & - & 2.819 & 0.005 \\
\hline Internet dependency & 1.075 & 0.033 & 0.898 & 32.953 & 0.000 \\
\hline
\end{tabular}

According to the results of table 3 and given that the significance level of the test error is less than 0.01, it can be said that internet dependency has a significant effect on the loneliness of the student- teachers of the Adiyaman University of 
Turkey. Also, the beta coefficient shows that Internet dependency 0.898 predicts student-teachers' loneliness variations.

Table 4: Results of $t$ test with two independent groups for hypothesis 2 of the research

\begin{tabular}{lllllllll}
\hline & Sex & $\mathrm{N}$ & $\mathrm{SD}$ & $\mathrm{M}$ & $\mathrm{MD}$ & $\mathrm{T}$ & $\mathrm{df}$ & Sig. \\
\hline Dependency & Female & 150 & 0.469 & 3.09 & 0.27 & 4.53 & 170 & 0.000 \\
to internet & Male & 160 & 160 & 0.421 & & & & \\
\hline
\end{tabular}

Given the significant level of Internet dependency for university student-teachers of Adiyaman University of Turkey, which is less than 0.05 , it can be said that there is a difference between student- teachers and girl-boy teachers' internet dependencies. And as the average difference between the two groups is clear, the average student Internet affiliation male teachers is higher than the average student affiliation - the female teacher, which is also the result of the difference.

Table 5. Results of $t$ test with two independent groups for hypothesis 3 of the research

\begin{tabular}{lllllllll}
\hline & Sex & N & SD & M & MD & T & df & Sig. \\
\hline Feeling & Female & 150 & 0.517 & 3.35 & 0.26 & 3.48 & 170 & 0.001 \\
lonely & Male & 160 & 0.603 & 3.08 & & & &
\end{tabular}

With regard to the meaningful level of loneliness for student- teachers of the Adiyaman University of Turkey, which is less than 0.05 , it can be said that there is a difference between the student's loneliness of female and male studentteachers. And as the average difference between the two groups is clear, the average student's sense of loneliness, the female teachers is higher than the average student loneliness of the male's teachers, which is the result of this difference.

\section{Conclusion}

In this research, the impact of Internet dependency on students' loneliness of student- teachers of Adiyaman University was studied. Also, the difference between Internet dependency and loneliness was studied among student- teachers of the Adiyaman University. The results showed that correlation coefficient between internet dependency of student-teachers' loneliness of Adiyaman University equal to 0.898 and the coefficient of determination is 0.807 . Considering that the significance level of the test error was less than 0.01 , it could be said that the dependence to the internet has a significant impact on student- teachers' loneliness of Adiyaman University, and the beta coefficient shows that Internet dependency 0.898 predicts the change in student- teachers' loneliness. In explaining this hypothesis, it can be said that with the increasing dependence on the internet among students, their sense of loneliness will eventually increase. The results showed that there was a significant level of Internet dependency for student- teachers of Adiyaman University of Turkey, who was less than 0.05 , and it can be said that there is a difference between female and male students and teachers' internet dependency. And as the average difference between the two groups was clear, the average male student- teachers' internet dependency is higher than the average female students and teachers' internet dependency, which is the result of the difference. In explaining this hypothesis, it can be said that university male student- teachers dependency is more than female student-teachers' internet dependency. The results showed that there was a significant level of loneliness for student- teachers of Adiyaman University which was less than 0.05 , and it can be said that there is a difference between male and female student- teachers; loneliness feeling. And as the average difference between the two groups was clear, the average female student-teachers' sense of loneliness is higher than male ones, which is the result of the difference. In explaining this issue, it can be said that female student-teachers of university feel loneliness more than the males' ones.

\section{References}

Bipeta, R., Yerramilli, S. S., Karredla, A. R., \& Gopinath, S. (2015). Diagnostic Stability of Internet Addiction in Obsessive-compulsive Disorder: Data from a Naturalistic One-year Treatment Study. Innov Clin Neurosci, 14-23.

Cacioppo, J. T., Hawkley, L. C., \& Thisted, R. A. (2010). Perceived social isolation makes me sad: 5-year cross-lagged analyses of loneliness and depressive symptomatology in the Chicago Health, Aging, and Social Relations Study. Psychol Aging, 25(2), 453-463. https://doi.org/10.1037/a0017216

Cacioppo, S., Grippo, A. J., London, S., Goossens, L., \& Cacioppo, J. T. (2015). Loneliness: clinical import and interventions. Perspect Psychol Sci., 10(2), 238-249. https://doi.org/10.1177/1745691615570616

Chou, K. L., Cacioppo, J. T., Kumari, M., \& Song, Y. Q. (2014). Influence of social environment on loneliness in older adults: moderation by polymorphism in the CRHR1. Am. J. Geriatr Psychiatry, 22(5), 510-518. https://doi.org/10.1016/j.jagp.2012.11.002

Coyle, C. E., \& Dugan, E. (2012). Social isolation, loneliness and health among older adults. J. Aging Health, 24(8), 1346-1363. https://doi.org/10.1177/0898264312460275 
Floros, G., Siomos, K., Stogiannidou, A., Giouzepas, I., \& Garyfallos, G. (2014). Comorbidity of psychiatric disorders with Internet addiction in a clinical sample: the effect of personality, defense style and psychopathology. Addict Behav,39, 1839-1845. https://doi.org/10.1016/j.addbeh.2014.07.031

Goossens, L., van Roekel, E., Verhagen, M., Cacioppo, J. T., Cacioppo, S., Maes, M., \& Boomsma, D. I. (2015). The genetics of loneliness: linking evolutionary theory to genome-wide genetics, epigenetics, and social science. Perspect Psychol Sci., 10(2), 213-226. https://doi.org/10.1177/1745691614564878

Hawkley, L. C., \& Cacioppo, J. T. (2010). Loneliness matters: a theoretical and empirical review of consequences and mechanisms. Ann. Behav. Med., 40(2), 218-227. https://doi.org/10.1007/s12160-010-9210-8

Hwang, J. Y., Choi, J. S., Gwak, A. R., Jung, D., Choi, S. W., Lee, J., ... Kim, D. J. (2014). Shared psychological characteristics that are linked to aggression between patients with Internet addiction and those with alcohol dependence. Ann Gen Psychiatry, 13, 6-19. https://doi.org/10.1186/1744-859X-13-6

Kim, S. J., Park, D. H., Ryu, S. H., Yu, J., \& Ha, J. H. (2013). Usefulness of Young's Internet addiction test for clinical populations. Nord J Psychiatry;67:393-399. https://doi.org/10.3109/08039488.2012.748826

King, D. L., Delfabbro, P. H., Griffiths, M. D., \& Gradisar, M. (2012). Cognitive-behavioral approaches to outpatient treatment of internet addiction in children and adolescents. J. Clin. Psychol., 68, 1185-1195. https://doi.org/10.1002/jclp.21918

Koh, Y. S. (2015). The Korean national policy for Internet addiction. In: Montag C, Reuter M, editors. Internet addiction. Neuroscientific approaches and therapeutic interventions. London: Springer. pp. 219-234. https://doi.org/10.1007/978-3-319-07242-5_13

Kuss, D. J., \& Griffiths, M. D. (2015). Internet addiction in psychotherapy. London: Palgrave. https://doi.org/10.1057/9781137465078

Lopez-Fernandez, O. (2015). How has Internet addiction research evolved since the advent of Internet Gaming Disorder? An overview of cyberaddictions from a psychological perspective. Curr. Addiction. Rep., 2, 263-271. https://doi.org/10.1007/s40429-015-0067-6

Masi, C. M., Chen, H. Y., Hawkley, L. C., \& Cacioppo, J. T .(2011). A metaanalysis of interventions to reduce loneliness. Pers. Soc. Psychol. Rev., 15(3), 219-266. https://doi.org/10.1177/1088868310377394

Müller, K. W., Beutel, M. E., \& Wölfling, K. (2014). A contribution to the clinical characterization of Internet addiction in a sample of treatment seekers: validity of assessment, severity of psychopathology and type of co-morbidity. Compr. Psychiatry, 55, 770-777. https://doi.org/10.1016/j.comppsych.2014.01.010

Poli, R., \& Agrimi, E. (2012). Internet addiction disorder: prevalence in an Italian student population. Nord. J. Psychiatry, 66, 55-59. https://doi.org/10.3109/08039488.2011.605169

Qualter, P., Vanhalst, J., Harris, R., van Roekel, E., Lodder, G., Bangee, M., Maes, M., \& Verhagen, M. (2015). Loneliness across the life span. Perspect Psychol Sci, 10(2), 250-264. https://doi.org/10.1177/1745691615568999

Russell, D., Peplau, L. A., \& Cutrona, C. E. (1980). The revised UCLA Loneliness Scale: Concurrent and discriminant validity evidence. Journal of Personality and Social Psychology, 39, 472-480. https://doi.org/10.1037/0022-3514.39.3.472

Santos, V., Nardi, A. E., \& King, A. L. (2015). Treatment of internet addiction in patient with panic disorder and obsessive compulsive disorder: a case report. CNS Neurol Disord Drug Targets, 14, 341-344. https://doi.org/10.2174/1871527314666150225123532

Shankar, A., Hamer, M., McMunn, A., \& Steptoe, A. (2013). Social isolation and loneliness: relationships with cognitive function during 4 years of follow-up in the English Longitudinal Study of Ageing. Psychosom Med., 75(2), 161-170. https://doi.org/10.1097/PSY.0b013e31827f09cd

Tonioni F, Mazza M, Autullo G, Cappelluti R, Catalano V, Marano G, Fiumana V, Moschetti C, Alimonti F, Luciani M, et al. (2014). Is Internet addiction a psychopathological condition distinct from pathological gambling? Addict Behav.,39, 1052-1056. https://doi.org/10.1016/j.addbeh.2014.02.016

VanderWeele, T. J., Hawkley, L. C., Thisted, R. A., \& Cacioppo, J. T. (2011). A marginal structural model analysis for loneliness: implications for intervention trials and clinical practice. J. Consult Clin. Psychol., 79(2), 225-235. https://doi.org/10.1037/a0022610

Victor, C. R., \& Yang, K. M. (2012) The prevalence of loneliness among adults: a case study of the United Kingdom. J. Psychol., 146(1-2), 85-104. https://doi.org/10.1080/00223980.2011.613875 
Victor, C., Scambler, S., Bond, J., \& Bowling, B. (2000). Being alone in later life: loneliness, social isolation and living alone. Rev. Clin. Gerontol, 10(4), 407-417. https://doi.org/10.1017/S0959259800104101

Winkler, A., Dörsing, B., Rief, W., Shen,Y., \& Glombiewski, J. A. (2013). Treatment of internet addiction: a meta-analysis. Clin. Psychol .Rev., 33, 317-329. https://doi.org/10.1016/j.cpr.2012.12.005

Wölfling, K., Beutel, M. E., Dreier, M., \& Müller, K. W. (2015). Bipolar spectrum disorders in a clinical sample of patients with Internet addiction: hidden comorbidity or differential diagnosis? J. Behav. Addict., 4, 101-105. https://doi.org/10.1556/2006.4.2015.011

Xu, J., Shen, L. X., Yan, C. H., Hu, H., Yang, F., Wang, L., Zhang, J. (2012). Personal characteristics related to the risk of adolescent internet addiction: a survey in Shanghai, China. BMC Public Health, 12, 1106-1117. https://doi.org/10.1186/1471-2458-12-1106

Young, K. S. (1996). Internet addiction: The emergence of a new clinical disorder. CyberPsychology and Behavior, 1(3), 237-244. https://doi.org/10.1089/cpb.1998.1.237

\section{Copyrights}

Copyright for this article is retained by the author(s), with first publication rights granted to the journal.

This is an open-access article distributed under the terms and conditions of the Creative Commons Attribution license which permits unrestricted use, distribution, and reproduction in any medium, provided the original work is properly cited. 